RESEARCH AND PRACTICE

\title{
Evaluation of a diabetes prevention program for rural citizens
}

\author{
Barbara B. Kawulich, $\mathrm{PhD}^{1}$, Diana Mindrila, $\mathrm{PhD}^{1}$, and Gina Brandenburg, MS, CHES \\ ${ }^{1}$ University of West Georgia, Carrollton, GA, and ${ }^{2}$ Tanner Health System, Carrollton, GA
}

\begin{abstract}
Background: Georgia has one of the highest rates of diabetes in the US. Obesity and inactivity contribute to the onset of this disease. Tanner Health System addressed the obesity epidemic in three rural counties of Georgia through a 16-week diabetes prevention program (DPP) for 176 residents. This study evaluated the effectiveness of the DPP.
\end{abstract}

Methods: The multiple methods design of this project used pre- and post-surveys from January/February, 2014, classes to determine diabetes-related lifestyle factors, 11 mid-point telephone interviews, and focus groups with 17 members to identify lifestyle changes that were implemented. Additionally, initial and final measurements of body mass index (BMI), number of sessions attended, and average number of minutes of physical activity (PA) were obtained for 175 participants in classes held in January/February and June/August, 2014.

Results: A paired samples $t$-test showed statistically significant decreases in BMI from initial to final weigh-ins: $t_{(175)}=-7.82$, $p<0.001$. Regression analyses revealed that the number of sessions attended was a statistically significant predictor of BMI loss $(p<0.001)$, explaining $13.5 \%$ of the variance. PA was also a significant predictor of BMI differences $(p<0.05)$, accounting for approximately $5 \%$ of the variation. Pearson product moment correlation coefficients indicated that BMI decreased as the number of sessions increases $(r=-.0367, p<0.001)$ and as the number of minutes of PA increases $(r=-.228, p$ $<.05$ ). After completing the DPP, participants had lower blood glucose levels and were able to lower dosages of medicines. They also had decreased blood pressure and blood cholesterol.

Conclusions: Participation in the DPP reduced risk factors associated with the onset of diabetes through weight loss, healthy eating, and increased exercise. Course content and participation encouraged accountability of participants.

Keywords: diabetes prevention; obesity; rural health

\section{INTRODUCTION}

In 2013, diabetes was listed as the seventh leading cause of death in the U.S. This disease is a major cause of heart disease and stroke, raising the risk for diabetic patients by two to four times more than patients without diabetes (Centers for Disease Control and Prevention (CDC), 2012, 2015a). In the U.S., 67\% of patients with diabetes also have high blood pressure. Diabetics with high blood pressure, high cholesterol levels, and who smoke have an increased risk of heart disease and stroke. Other complications associated with diabetes include loss of vision, kidney failure, and amputation of extremities (CDC, 2011). Another outcome of diabetes is neuropathy, which can lead to amputation if left unaddressed (Callaghan, Little, Feldman, \& Hughes, 2012).

The rates of serious health events, such as limb amputation, renal failure, and hyperglycemic crises have decreased since the mid-1990s, in part, because of better control of high blood pressure and high cholesterol and because of smoking cessation. The CDC notes that the decline in serious health events may also result from improvements in control of blood glucose, early detection, and better preventive care and maintenance. The complications associated with diabetes are addressed by controlling the hemoglobin A1c levels of patients. The A1c test provides the average of a person's blood glucose levels over the past three months by measuring the attachment of glucose to hemoglobin A1c; an A1c value below 5.7 percent is considered normal (National Institute of Diabetes and Digestive and Kidney Diseases, 2014).

Risk factors for diabetes include aging, physical inactivity, heredity, socioeconomic conditions, obesity, race, and ethnicity (CDC, 2015a). Obesity in people with Type 2 diabetes correlates with problems involving control of blood sugar, blood pressure, and cholesterol (CDC, 2015a). There is a disproportionately higher incidence of the disease among American Indians and Alaskan Natives (16.1\%), non-Hispanic Blacks (12.6\%), Hispanics (11.8\%), and Asian Americans (8.4\%) aged 20 or older, relative to their non-Hispanic White counterparts (7.1\%) (CDC, 2012). From 1980 to 2014, the number of people in the U.S. diagnosed with diabetes has quadrupled (CDC, 2015c) from 5.5 million to 22 million. This increase mirrors similar trends that show increases in obesity, lack of exercise, and aging. 
The rate of diagnosed diabetes in Georgia has doubled, from $5.2 \%$ in 1994 to $10.4 \%$ in 2014 (CDC, 2015b). The CDC estimates that $11.4 \%$ of Carroll County residents, $10.4 \%$ of Haralson County residents, and $10.4 \%$ of Heard County residents have been diagnosed with diabetes (age-adjusted percentages for 2012) (CDC, 2015d). The CDC provides funding and technical assistance to each state in the U.S. to support programs, such as the National Diabetes Prevention Program, which was established through the Affordable Care Act, to fight the rise in incidences of diabetes through prevention programs targeting people at risk of developing the disease.

\section{Diabetes Prevention Research}

Various literature reviews indicate that appropriate actions can result in improved outcomes for pre-diabetic and diabetic patients. For example, a meta-analysis of studies that included diet modification and aerobic/resistance training showed, for pre-diabetic patients, a modest effect for weight loss and improved fasting blood glucose, glucose tolerance, and dietary and exercise outcomes (Aquiar, Morgan, Collins, Plotnikoff, \& Callister, 2014). For prediabetic patients, pharmacological (metformin) and lifestyle interventions (education about lifestyle changes, such as healthy nutrition and increased physical activity (PA)) have been shown to reduce A1c measures, BMI, total body weight, and waist circumference (Alibasic, Ramic, \& Alic, 2013); in this small study ( $N=60,20$ per group), lifestyle education was more effective than metformin, and either was more effective than no treatment. Similarly, in a study of 241 overweight/obese pre-diabetic patients, those with BMI > 35 were more successful in reducing mean BMI, body weight, and waist circumference when they participated in coach-led group intervention education $(\mathrm{N}=79)$ or self-directed interventions $(\mathrm{N}=81)$ relative to those with no treatment beyond usual care $(\mathrm{N}=80)$ (Azar, Xiao, \& Ma, 2013). Further, participation in a weight-loss program or DPP affects those who support the patients participating in the program. For those who support program participants (such as friends and family members), there are positive influences, particularly weight loss, associated with changes in eating habits (Bishop, Irby, Isom, Blackwell, Vitolins, and Skelton (2013)).

\section{Factors influencing participation}

A synthesis of seventeen studies (Johnson, Jones, Freeman, Woods, Gillett, Goyder, \& Payne, 2013) indicated that DPPs can be used to deliver outcomes of increased weight loss to reduce diabetes risk. Yet, participation by those at risk can be problematic. For example, a study of 89 European women evaluated the effectiveness of an established lifestyle intervention in comparison to standard care for delaying diabetes onset in women who had recent gestational diabetes mellitus (Infanti, O’Dea, Gibson, McGuire, Newell, Glynn, O’Neill, Connolly \& Dunne, 2014). Risk factors analyzed included smoking, fruit/vegetable intake, exercise, family history of diabetes, glucose values, BMI, use of insulin during pregnancy, and age at delivery. Women over age 34 were more likely to participate, but women who had used insulin during pregnancy were less likely to participate. Barriers to participation were accessibility, affordability, and practicality of the intervention.

Another study (Seidel, Pardo, Estabrooks, You, Wall, Davy, \& Almeida, 2014) focused on improving reach by identifying patient preferences for various aspects of a local DDP. Surveys of 142 patients at two family medical clinics indicated that $83 \%$ preferred a technology-based program over a classroom-based program and that Whites were less likely to prefer a technology-based program. Patients with lower socioeconomic status (SES) were more likely to prefer a technology-based or telephone-based program. In other studies, patients with lower SES were less likely to participate in a DPP (Stellefson, Chaney, \& Chaney, 2008; Zickuhr \& Smith, 2012).

In Australia, those most likely to participate in a DPP were those who were physically inactive and who had a family history of diabetes or history of high blood glucose levels (Laws, Vita, Venugopal, Rissel, Davies, and Colabiuri, 2012). Less likely to enroll were those who smoked, who were born in a country with a high risk for diabetes, who were taking medicine to lower blood pressure, and who ate few fruits and vegetables.

In 2012, Tanner Health System (Tanner), which serves the three-county area of Carroll, Haralson, and Heard Counties in west Georgia, received a Community Transformation Grant from the CDC (Community Transformation Grant \# 1H75DP004602-01). This two-year grant addressed eleven initiatives that Tanner and its community partners implemented in 2013-2014, one of which related to diabetes prevention. Since the prevention of disease for rural populations is not well documented, the purpose of the present evaluation was to determine if engagement in a DPP was effective in helping rural residents make lifestyle changes to prevent the onset of diabetes. The objectives guiding the evaluation were summarized as follows: 1) program participants will improve their BMI; and 2) program participants will make lifestyle changes, such as healthier eating habits and increased PA. Since the west Georgia area had not been previously included in such an evaluation, the intent was to share findings related to this population to fill a gap in the existing literature on diabetes prevention. The research questions guiding this evaluation were as follows:

- Is participation in a DPP effective for helping participants improve their BMI?

- Is participation in a DPP effective for helping participants implement healthier lifestyle changes?

- What challenges exist for participants in a DPP in implementing healthier lifestyle changes?

\section{Theoretical Perspective}

The Prochaska transtheoretical model of stages of change (Prochaska, DiClemente, \& Norcross, 1992) provided a theoretical framework for the study. This model incorporates dimensions of change through various theoretical constructs to conceptualize intentional behavioral change. People make lifestyle changes in stages, and the Diabetes Prevention Program (DPP) is a well-researched, proven tool through which to initiate lifestyle changes for 
people who have been diagnosed as pre-diabetic or those who simply want to prevent the onset of diabetes (Diabetes Prevention Program Research Group, 2015). The five stages of change include pre-contemplation, contemplation, preparation, action, and maintenance. The model promotes the idea that changes occur over time. People who are not thinking about making a change are considered to be in the pre-contemplation stage, and they may actually avoid educational opportunities requiring that they think about their high-risk behaviors. At the contemplation stage, people become more aware of the benefits of making lifestyle changes, and they become more cognizant of the detriments of maintaining high-risk behaviors. The preparation stage involves those beginning to think about actions they might take to correct their high risk behaviors. At the action stage, people begin to modify their behaviors to improve their lifestyle. Maintenance is the stage at which people make modifications to their high-risk behaviors and strive to maintain their healthy lifestyles. Because participation in the DPP was voluntary, participants were considered to be in the contemplation phase.

\section{METHODS}

Prior to conducting this evaluation, the project was approved by the Institutional Review Board at the University of West Georgia. In November, 2013, a two-day (16-hour) DPP Lifestyle Coach Training was held, and a second training program was held in May, 2014, yielding 29 trained coaches. These interactive 2-day trainings, led by a Master Trainer, provided the lifestyle coaches with the skills, knowledge, and experience needed to facilitate the lifestyle change program. The training featured an interactive, small-group format with hands-on practice in group facilitation techniques. The content was focused on improving healthy lifestyle behaviors related to nutrition and PA.

To promote healthy lifestyle changes to prevent the onset of diabetes and related diseases, Tanner sponsored the 16-week DPP workshops in seven locations in the three-county area of Carroll, Haralson, and Heard Counties. DPP offered 16 weeks of core classes (one class session per week), followed by monthly meetings for one year to help participants maintain their progress. Because the grant ended in September, 2014, data were collected from follow-up weigh-ins monthly through September, 2014.

Participants for the DPP were recruited through a variety of venues, including the Get Healthy, Live Well website; social media; physician referral; and community outreach, including local churches and housing authorities. Eligibility for participation in the DPP classes included 18+ years old and BMI > 24. At least 50\% must have a documented diagnostic blood test indicating prediabetes, which included a fasting glucose of 100 to $125 \mathrm{mg} / \mathrm{kl}$ or an A1c of 5.7 to 6.4. Others were deemed eligible if they were at risk on the CDC prediabetes screening test. They were not required to reside in the three-county area; however, most did. A few worked in the three-county area but lived in surrounding counties.
In January/February, 2014, 77 participants registered for the classes to learn new strategies for healthy living and were weighed in at each session. Twelve completed four or fewer classes, and 50 (65\%) completed 13 to 16 class sessions. A second set of classes began in June, 2014, and additional classes were begun through August, 2014, for which 96 people registered.

\section{Procedures}

During the first week of the January/February courses, 47 participants responded to an online abbreviated Behavioral Risk Factor Surveillance System (BRFSS) survey to determine lifestyle factors related to diabetes. Since the BRFSS is lengthy, the evaluation team extracted 38 questions from the BRFSS that related to topics covered within the DPP curriculum, including access to health care, eating habits, PA, current state of health, and tobacco use, among others. At the end of the January/February core classes of the DPP program, 16 had completed the abbreviated BRFSS online.

At the mid-point of the core classes, telephone interviews were conducted by doctoral students enrolled in a qualitative research course at the University of West Georgia. Eleven of the 47 survey participants called by these students were willing to participate in the interviews. To elicit explanations of their survey responses, the guide developed for the interviews was based on their responses to the abbreviated BRFSS survey. During July, 2014, 17 of the January/February class participants engaged in focus groups to determine what lifestyle changes were implemented and to elicit their perceptions about the program. They were recruited through their DPP classes and were given a \$20 gift card for participating.

Participants were weighed at each class session and monthly following the end of the 16-week program through September, the end of the data collection period.

Between two and 132 assessments were recorded for each individual. Participants took classes beginning in January/February, June, or August. After data cleaning, the final sample included a total of 175 individuals who were measured at least twice. For each individual, the first and the last weight assessments were used to determine BMI before and after participation in the DPP. Additionally, for each individual, the number of sessions attended was recorded, and the average number of minutes of PA was calculated.

\section{RESULTS}

Data from the abbreviated BRFSS survey were summarized to gain information about the participants' lifestyle before entering the DPP $(N=47)$. At the beginning of the program, most of them had been told by a health professional that they had high blood pressure (63.8\%) and high blood cholesterol (57.4\%). Although most respondents reported eating fruit or vegetables daily or weekly, only $18.7 \%$ reported engaging in physical activities during the past 
month. Among these respondents, the predominant PA was walking (61.7\%). The distribution of responses for all survey items is reported in the Appendix.

Question 1: Was involvement in the DPP effective for helping participants improve their BMI?

On average, BMIs decreased by approximately one point $(\sim 3 \%)$. BMI differences were consistent across genders (Table 1). A paired samples $t$ test for the entire sample showed that decreases in BMI were statistically significant: $\mathrm{t}(175)=-7.82, p<0.001$ (Table 2).
Table 1. Mean Initial and Final BMI

\begin{tabular}{|l|l|l|l|}
\hline & & $\boldsymbol{M}$ & SD \\
\hline Initial BMI & All & 34.52 & 7.45 \\
\hline & Females & 34.87 & 7.89 \\
\hline & Males & 33.84 & 5.70 \\
\hline Final BMI & All & 33.47 & 7.25 \\
\hline & Females & 33.81 & 7.78 \\
\hline & Males & 32.46 & 5.48 \\
\hline
\end{tabular}

Table 2. Paired Samples t Test

\begin{tabular}{|c|c|c|c|c|c|c|c|c|}
\hline & \multicolumn{5}{|c|}{ Paired Differences } & \multirow[t]{2}{*}{$t$} & \multirow[t]{2}{*}{$d f$} & \multirow[t]{2}{*}{$p$} \\
\hline & $\mathbf{M}$ & SD & SE & & & & & \\
\hline $\begin{array}{l}\text { Final_BMI - } \\
\text { Initial_BMI }\end{array}$ & -1.05 & 1.78 & 0.13 & -1.31 & -0.78 & -7.82 & 175 & 0.000 \\
\hline
\end{tabular}

This analysis included individuals who attended 2-20 sessions $(\mathrm{N}=176)$. As the number of attended sessions increased, the BMI decreased $(r=-0.367, p<0.001)$. The number of attended sessions (NS) explained $13.5 \%$ of the variance in BMI differences $\left(F_{(1,174)}=34.776, p<0.001\right)$ and was a significant predictor of BMI loss $\left(\beta=-367, t_{(174)}\right.$ $=-5.186, p<0.001)$. Regression equation: BMI difference $=0.052-0.109 * \mathrm{NS}$

Regarding the relationship to PA, 83 individuals did not have a recorded number of minutes of PA and could not be included in this analysis, because they had only begun the program in August, and the PA aspect of the program was not covered at that point in their classes. A Pearson Product Moment correlation coefficient was computed to determine the degree of association between BMI differences and the recorded minutes of PA at the last assessment. There was a statistically significant correlation coefficient of $r=-0.228$ ( $p$ $<0.05$, $N=93$ ). This coefficient had a negative value, showing that decreases in BMI were associated with increased numbers of minutes of PA. Regression analysis showed that the number of minutes of PA explained $5.2 \%$ of the variance in BMI differences $\left(F_{(1,91)}=10.149, p<0.05\right)$ and was a statistically significant predictor of BMI loss $(\beta=$ -0.228, $\left.t_{(91)}=-2.238, p<0.05\right)$. Regression equation: $\mathrm{BMI}$ difference $=-0.911-0.002 * \mathrm{PA}$

\section{Question 2: Was involvement in the DPP effective for helping participants implement healthier lifestyle changes?}

In the qualitative findings, mid-point interview data collected from interviews with 11 participants revealed that six perceived positive changes in their health status, which they attributed to changes in diet and exercise. One indicated a negative change in health status, which s/he attributed to not monitoring food and sugar intake; this individual stated, "I'm in the program now, so I am trying to correct that. I am eating better, getting more exercise, and watching my portions.” The other five indicated no change in their health status since beginning the program. Three of these attributed this lack of change to pre-existing health conditions, such as heart ailments and limited mobility; the other two indicating no change in health status stated that their health remained good.
Blood Pressure

High blood pressure generally accompanies diabetes (CDC, 2011). Participants were asked on the initial abbreviated BRFSS survey if they had ever been diagnosed with high blood pressure, to which $63.8 \%$ indicated that they had, and $57.4 \%$ stated that they were taking medication to control it. During the mid-point interviews, the 11 interviewees were asked what they thought had contributed to their diagnosis of high blood pressure. Three themes were identified: genetic predisposition, diet and exercise, and stress. Five of the 11 interviewees attributed their diagnosis of high blood pressure to genetic predisposition. As one stated, "heredity in the DNA on both sides of the family" contributed to his/her diagnosis;, another participant responded, "I really don't know, except it is a family inherited thing." Five interviewees indicated that poor diet and lack of exercise contributed to their diagnosis. Three of these attributed their diagnosis of high blood pressure to weight. Stress was mentioned as a contributing factor for two of the interviewees; one noted, "You know, when you have a demanding job, the stress can get a hold of you real good." Several interviewees mentioned that the diagnosis of high blood pressure meant having to take medications and adjust their eating habits, such as eating "less fatty foods" and eating a more low-carb diet. On the post-survey, 13 reported having been diagnosed with high blood pressure, and all were taking medication to address the condition. During focus groups conducted after completing the core classes, several mentioned that they had been able to decrease their blood pressure to the extent that their doctors had prescribed a lower dosage of their blood pressure medicine or discontinued their medication.

\section{Cholesterol}

In addition to high blood pressure, high cholesterol is often a problem for people with diabetes. On the initial survey, $57.4 \%$ of the respondents indicated that they had been told by a healthcare professional that their blood cholesterol levels were high. In the mid-point interviews, 7 of the 11 interviewees indicated having high cholesterol. All attributed it to poor diet and lack of exercise. All interviewees with this diagnosis were managing their cholesterol through medication and a change in eating habits. At the end of the DPP core classes, one of the focus 
group members stated that his/her cholesterol medication had been reduced. Changes in diet made to reduce their cholesterol levels included eating less meat and generally eating more healthy foods, including more whole grains and eating more fruits and vegetables and less fatty foods. At the end of the DPP core classes, many indicated that they were eating more beans as a meat substitute and eating more dark green and orange vegetables.

In addition to eating healthier, some indicated that they had increased their levels of exercise. Whereas at the beginning of DPP classes, they typically walked or used an elliptical machine or stationary bicycle, by the end of the classes, they had increased the number of minutes per week spent exercising and had expanded their choices to include muscle strengthening exercises, aerobics, gardening, and walking.

\section{Question 3: What challenges exist for DPP participants in implementing healthier lifestyle changes?}

When asked about the challenges they experienced in implementing a healthier lifestyle, five of the 11 interviewees reported taking multi-vitamins to gain nutrients ordinarily provided by fruits and vegetables. When asked why they did not simply eat more fruits and vegetables, they mentioned such barriers as:

- Cost - Several mentioned that fruits and vegetables were expensive grocery items;

- Accessibility to the grocery store - One stated that "having access to the store regularly would be helpful." In this rural area, there are food deserts that make it difficult for citizens who have no transportation to access grocery stores or other outlets where healthy food options are available; and

- A low carbohydrate lifestyle - Two equated eating less junk food with having a low- carbohydrate lifestyle. They indicated that they were trying to eat fewer foods containing simple carbohydrates and more that contained complex carbohydrates.

One stated that, since beginning the DPP, he/she had begun to substitute fruit for potato chips, cakes, and cookies. When asked what would help them to increase their consumption of fruits and vegetables, one explained that, "only if I turned into a vegetarian would I consume more fruits and vegetables," meaning that he/she was already eating considerable amounts of fruits and vegetables. Another interviewee stated that he/she was not in the habit of eating fruit as a snack, as he/she did not think about it, but knew he/she should do so. Seven of the 11 stated that they were interested in learning more about healthy eating. Class discussions that focused on nutritional aspects of the DPP included, among other topics, substituting beans for meat or choosing lean meats instead of fatty meats, sharing recipe makeovers to make meals healthy, and learning how to read package labels. This aspect of the course was mentioned by most of the interviewees as being useful and interesting.

\section{Focus Group Results}

With participants from the January/February DPP classes, focus group discussions were held in July 2014, to determine what they perceived to be the benefits of the DPP and whether they were maintaining a healthy lifestyle after six months in the program. The most helpful aspect of the DPP, they stated, was the accountability, because it motivated them to think about their health through the weekly weigh-ins and daily food logs they were required to keep. Having others in the class, including the instructor, know what they were doing helped them to maintain a weekly routine. They found the class lessons to be manageable and derived a better understanding of how to maintain their health through learning about grams of fat, portion control, and mindful eating, and through understanding changes in the body. They mentioned that they appreciated the access to professional support, such as dietitians, through the DPP. They enjoyed the opportunities to interact with their lifestyle coach instructor as a way to stay focused. They also mentioned that their family and friends were benefitting from what they had learned and were beginning to adopt healthier eating patterns. They said they were reaching their goals for attending the program, which included losing weight; preventing diabetes; and, with professional help, changing dietary habits and discontinuing medications. The reasons they stated that they would continue to maintain a healthy lifestyle were to avoid health problems and to maintain the noticeable physical and health improvements that they (and others) were seeing. They found the dietary advice and exercise regimen to be easy to follow and enjoyed the use of the MyFitnessPal app, which enabled them to track their exercise, track nutrient levels, and prepare recipes that fit their dietary needs. They benefitted from hearing others' stories about successful lifestyle changes, and they enjoyed sharing recipes with each other and mentioned wanting more recipes and culinary instruction. A challenge occurred when participants reached a plateau in their weight loss, causing loss of momentum and frustration. One mentioned being overconfident about the ease of the program, resulting in a loss of focus and commitment. One mentioned having metabolic issues and weight loss problems because of the program's focus on vegetables, resulting in a lack of caloric intake.

\section{DISCUSSION}

Considering the findings through Prochaska's transtheoretical model of stages of change, it appears that participants moved from the contemplation stage to the preparation stage and, in some cases, into the action stage. At the beginning of the DPP, the participants, all of whom volunteered, were considered to be at the contemplation stage, as they were aware that substantial lifestyle changes were needed. As they progressed through the program and moved into the preparation stage, they began to make decisions to change their risky lifestyle behaviors. Many of them moved, or were in the process of moving, to the action stage, where they began to modify their behaviors. A few might be deemed to be at the maintenance stage, where they were making modifications and striving to maintain their healthy lifestyle without relapsing. 
The focus group members enthusiastically shared their progress, indicating that the lifestyle changes made were easy to implement and would carry over into their everyday lives. Without a follow-up collection of data, however, it is difficult to make a judgment about whether they maintained their behavioral changes. The results of this study indicate that participation in the DPP program was effective in providing these rural citizens with information to facilitate making positive lifestyle changes. Further, those who completed the program lost weight, which improved their BMI, thereby reducing their risk for diabetes and related diseases. Participation in the DPP was associated with a significant decrease in BMI, and more sessions attended and the more exercise were associated with greater reductions in their BMI. Participants reported that their improved nutrition and PA habits were resulting in lowered blood pressure and cholesterol.

The benefits included the accountability the DPP provided, the informative content about how to become healthier, the access to professional and peer support, and the impact that their participation made on their health (decreases in weight, cholesterol, blood pressure, A1c, and blood glucose levels). Challenges included the cost of fresh fruits and vegetables, access to grocery stores, and eating a low-fat diet with complex carbohydrates. In sum, participation in the DPP resulted in weight loss and lower BMI, which have the potential for reducing risk factors associated with diabetes.

Through the program, many participants promoted healthy eating and increased exercise to their friends and family members, which has the potential for having enhancing their wellness. More DPP and other health-related programs should be offered as a community service to address healthrelated issues, such as weight loss, healthy nutrition, and PA, the lack of which is directly related to diabetes, high blood pressure, and high cholesterol. These programs need to be accessible to all citizens in this rural area; outreach may need to target underserved populations who would benefit from the information contained in DPP. The west Georgia community has begun to address these needs through a variety of avenues, such as expanding the Green Belt walking trail, promoting "walk to school" programs, establishing community gardens, addressing nutrition in the school systems, and continuing the DPP. These efforts provide a good start toward addressing obesity and other related health problems in the community, but the need for more action continues.

\section{Acknowledgements}

This research study was supported by Tanner Health System, which received a Community Transformation Grant (\#1H75DP004602-01) from the Centers for Disease Control and Prevention. We wish to acknowledge the assistance of University of West Georgia graduate students and of the $\mathrm{E}^{2} \mathrm{C}^{2}$ evaluation group for assistance in data collection and analyses. We also acknowledge the support of Ms. Denise Taylor, Chief Community Health, Strategy, and Brand Officer, Tanner Health System.

\section{References}

Aguiar, E., Morgan, P., Collins, C., Plotnikoff, R., \& Callister, R. Efficacy of interventions that include diet, aerobic and resistance training components for type 2 diabetes prevention: A systematic review with meta-analysis. International Journal of
Behavioral Nutrition and Physical Activity, 2014, 11(2): 1-10. doi: 10.1186/1479-5868-11-2

Alibasic, E., Ramic, E., \& Alic, A. Prevention of diabetes in family medicine. Materia Socio Medica, 2013, 25(2): 80-82. doi: $10.5455 / \mathrm{msm} .2013 .25 .80-82$

Azar, K., Xiao, L., \& Ma, J. Baseline obesity status modifies effectiveness of adapted diabetes prevention program lifestyle interventions for weight management in primary care. BioMed Research International, 2013: 1-

7. http://dx.doi.org/10.1155/2013/191209

Bishop, J., Irby, M., Isom, S., Blackwell, C., Vitolins, M., Skelton, J. Diabetes prevention, weight loss, and social support: Program participants' perceived influence on the health behaviors of their social support system. Family and Community Health, 2013, 36 (2): 1-17. doi: 10.1097/FCH.0b013e318282b2d3

Callaghan, B., Little, A., Feldman, E., \& Hughes, R. Enhanced glucose control for preventing and treating diabetic neuropathy (Review). Cochrane Database of Systematic Reviews, 2012, Issue 6, Art. No.: CD007543. doi: 10.1002/14651858.CD007543.pub2.

Centers for Disease Control and Prevention. National diabetes fact sheet: National estimates and general information on diabetes and prediabetes in the United States, 2011. Atlanta, GA: U.S. Department of Health and Human Services, Centers for Disease Control and Prevention. Retrieved from http://www.cdc.gov/diabetes/pubs/pdf/ndfs_2011.pdf

Centers for Disease Control and Prevention. Diabetes Report Card, 2012. Atlanta, GA: Centers for Disease Control and Prevention, US Department of Health and Human Services; 2012. Retrieved from http://www.cdc.gov/diabetes/pubs/pdf/diabetesreportcard.p $\underline{\mathrm{df}}$

Centers for Disease Control and Prevention. Diabetes Report Card, 2014. Atlanta, GA: Centers for Disease Control and Prevention, US Dept. of Health and Human Services; 2015a. Retrieved from http://www.cdc.gov/diabetes/pdfs/library/diabetesreportcar d2014.pdf

Centers for Disease Control and Prevention. Georgia: Diagnosed Diabetes, Aged Adjusted Rate (per 100), Adults - Total, 2013. Atlanta, GA: Centers for Disease Control and Prevention, US Dept. of Health and Human Services; 2015b. Retrieved from http://gis.cdc.gov/grasp/diabetes/DiabetesAtlas.html

Centers for Disease Control and Prevention. Number (in millions) of Civilian, Non-institutionalized Persons with Diagnosed Diabetes, United States, 1980-2014. Atlanta, GA: Centers for Disease Control and Prevention, US Dept. of Health and Human Services; 2015c. Retrieved

from http://www.cdc.gov/diabetes/statistics/prev/national/figper $\underline{\text { sons.htm }}$

Centers for Disease Control and Prevention. Diagnosed Diabetes Age-Adjusted Percentage, 2012). Atlanta, GA: Centers for Disease Control and Prevention, US Dept. of Health and Human Services; 2015d. Retrieved

from http://www.cdc.gov/diabetes/atlas/countydata/atlas.html?fil $\underline{\text { ter}=\text { filter4,Georgia\&indicator }=\mathrm{i} 3}$

Diabetes Prevention Program Research Group (2015). Long-term effects of lifestyle intervention or metformin on diabetes development and microvascular complications over 15-year follow-up: The Diabetes Prevention Program Outcomes Study. The Lancet. Diabetes \& Endocrinology, 3 (11), 866-875. doi: 10.1016/S2213-8587(15)00291-0

Infanti, J. J., O’Dea, A. O., Gibson, I., McGuire, B. E., Newell, J., Glynn, L. G., O’Neill, C., Connolly, S. B., \& Dunne, F. P. Reasons for participation and non-participation in a diabetes prevention trial among women with prior gestational diabetes mellitus (GDM). BMC Medical Research Methodology, 2014, 14 (13). doi: 10.1186/1471-2288-14-13

Johnson, M., Jones, R., Freeman, C., Woods, H., Gillett, M., Goyder, E., \& Payne, N. Can diabetes prevention programmes be translated effectively into real-world settings and still deliver 
improved outcomes? A synthesis of evidence. Diabetic Medicine, 2013, 30: 3-15. doi: 10.1111/dme.12018

Laws, R., Vita, P., Venugopal, K., Rissel, C., Davies D., \& Colagiuri, S. Factors influencing participant enrolment in a diabetes prevention program in general practice: Lessons from the Sydney diabetes prevention program. BMC Public Health, 2012, (12)822: 1-9. doi: 10.1186/1471-2458-12-822

National Institute of Diabetes and Digestive and Kidney Diseases. (2014). The A1C test and diabetes. Retrieved from http://www.niddk.nih.gov/health-information/healthtopics/diagnostic-tests/a1c-test-diabetes/Pages/index.aspx
Prochaska, J., DiClemente, C., \& Norcross, J. In search of how people change: Applications to addictive behaviors. American Psychologist, 1992, 47(9): 1102-1114. Retrieved

from http://www.ncbi.nlm.nih.gov/pubmed/1329589

Seidel, R., Pardo, K., Estabrooks, P., You, W., Wall, S., Davy, B., \& Almeida, F. Beginning a patient-centered approach in the design of a diabetes prevention program. International Journal of Environmental Research and Public Health, 2014, 11: 20032013. doi: 10.3390/ijerph110202003

Stellefson, M., Chaney, B., Chaney, D. The digital divide in health education: Myth or reality? American Journal of Health Education, 2008, 39(2): 106-112. doi: $10.1080 / 19325037.2008 .10599023$ 


\section{Appendix}

Results from the First Administration of the Tanner Community Transformation Grant Survey

These survey questions are taken directly from the BRFSS, a validated instrument of CDC, which can be retrieved at: http://www.cdc.gov/brfss/questionnaires/pdf-ques/2013\%20BRFSS_English.pdf

\begin{tabular}{|c|c|c|c|c|c|c|c|c|}
\hline & Poor & Fair & Good & $\begin{array}{l}\text { Very } \\
\text { Good }\end{array}$ & Excellent & $\begin{array}{c}\text { Don't } \\
\text { know/ Not } \\
\text { sure }\end{array}$ & $\begin{array}{c}\text { Refuse } \\
\text { to } \\
\text { answer }\end{array}$ & $\mathbf{N}$ \\
\hline $\begin{array}{l}1.1 \text { Would you say that, in general, } \\
\text { your health is ---? }\end{array}$ & $0.0 \%$ & $14.9 \%$ & $57.4 \%$ & $17.0 \%$ & $10.6 \%$ & $0.0 \%$ & $0.0 \%$ & 47 \\
\hline
\end{tabular}

\section{Section 1: Health Status}

Circle the number best representing your answer.

\section{Section 2: Health Care Access}

Circle the number best representing your answer.

\begin{tabular}{|c|c|c|c|c|c|}
\hline & No & Yes & $\begin{array}{l}\text { Don't } \\
\text { know/ Not } \\
\text { sure }\end{array}$ & $\begin{array}{l}\text { Refuse } \\
\text { to } \\
\text { answer }\end{array}$ & $\mathbf{N}$ \\
\hline $\begin{array}{l}\text { 2.1 Do you have any kind of health care coverage, including } \\
\text { health insurance, prepaid plans, such as HMOs, or government } \\
\text { plans such as Medicare or Indian Health Service? }\end{array}$ & $4.3 \%$ & $95.7 \%$ & $0.0 \%$ & $0.0 \%$ & 47 \\
\hline $\begin{array}{l}2.2 \text { Was there a time in the past } 12 \text { months when you needed to see a } \\
\text { doctor but could not, because of cost? }\end{array}$ & $78.7 \%$ & $21.3 \%$ & $0.0 \%$ & $0.0 \%$ & 47 \\
\hline
\end{tabular}

\begin{tabular}{|c|c|c|c|c|c|c|}
\hline & No & $\begin{array}{l}\text { Yes, } \\
\text { only } \\
\text { one }\end{array}$ & $\begin{array}{c}\text { More } \\
\text { than } \\
\text { one }\end{array}$ & $\begin{array}{c}\text { Don't } \\
\text { know/ Not } \\
\text { sure }\end{array}$ & $\begin{array}{l}\text { Refuse } \\
\text { to } \\
\text { answer }\end{array}$ & $\mathbf{N}$ \\
\hline $\begin{array}{l}\text { 2.3 Do you have one person you think of as your personal } \\
\text { doctor or health care provider? }\end{array}$ & $8.5 \%$ & $48.9 \%$ & $40.4 \%$ & $2.1 \%$ & $0.0 \%$ & 47 \\
\hline
\end{tabular}

\begin{tabular}{|l|c|c|}
\hline $\begin{array}{l}\text { 2.4 About how long has it been since you last visited a doctor for a routine checkup? A routine } \\
\text { checkup is a general physical exam, not an exam for a specific injury, illness, or condition. }\end{array}$ & N \\
\hline Never & $0.0 \%$ & 47 \\
\hline 5 or more years ago & $6.4 \%$ & 47 \\
\hline Within past 5 years (2 years but less than 5 years ago) & $6.4 \%$ & 47 \\
\hline Within past 2 years (1 year but less than 2 years ago) & $23.4 \%$ & 47 \\
\hline Within past year (anytime less than 12 months ago) & $63.8 \%$ & 47 \\
\hline Don't know/ Not sure & $0.0 \%$ & 47 \\
\hline Refuse to answer & $0.0 \%$ & 47 \\
\hline
\end{tabular}

\section{Section 3: Hypertension and Cholesterol Awareness}

Circle the number best representing your answer.

\begin{tabular}{|l|c|c|c|}
\hline & No & Yes & N \\
\hline $\begin{array}{l}\text { 3.1 Have you EVER been told by a doctor, nurse, or other health professional that you have } \\
\text { high blood pressure? }\end{array}$ & $36.2 \%$ & $63.8 \%$ & 47 \\
\hline
\end{tabular}

(if no, then skip to Question 3.3) 
3.2 If yes, are you currently taking medicine for your high blood pressure?

3.3 Blood cholesterol is a fatty substance found in the blood. Have you EVER had your blood cholesterol checked?

3.4 Have you EVER been told by a doctor, nurse or other health professional that your blood cholesterol is high?

\begin{tabular}{|c|c|c|c|c|}
\hline No & Yes & $\begin{array}{c}\text { Don't } \\
\text { know/ Not } \\
\text { sure }\end{array}$ & $\begin{array}{c}\text { Refuse } \\
\text { to } \\
\text { answer }\end{array}$ & $\mathbf{N}$ \\
\hline $4.3 \%$ & $57.4 \%$ & $0.0 \%$ & $0.0 \%$ & 47 \\
\hline $0.0 \%$ & $97.9 \%$ & $2.1 \%$ & $0.0 \%$ & 47 \\
\hline $38.3 \%$ & $57.4 \%$ & $4.3 \%$ & $0.0 \%$ & 47 \\
\hline
\end{tabular}

\begin{tabular}{|l|l|c|}
\hline 3.5 About how long has it been since you last had your blood cholesterol checked? & Percentage & N \\
\hline Never & $0.0 \%$ & 47 \\
\hline 5 or more years ago & $0.0 \%$ & 47 \\
\hline Within past 5 years (2 years but less than 5 years ago) & $4.3 \%$ & 47 \\
\hline Within past 2 years (1 year but less than 2 years ago) & $6.4 \%$ & 47 \\
\hline Within past year (anytime less than 12 months ago) & $87.2 \%$ & 47 \\
\hline Don't know/ Not sure & $2.1 \%$ & 47 \\
\hline Refuse to answer & $0.0 \%$ & 47 \\
\hline
\end{tabular}

\section{Section 4: Tobacco Use}

Circle the number best representing your answer.

\begin{tabular}{|c|c|c|c|c|c|}
\hline ( & No & Yes & $\begin{array}{c}\text { Don't } \\
\text { know/ Not } \\
\text { sure } \\
\end{array}$ & $\begin{array}{c}\text { Refuse to } \\
\text { answer }\end{array}$ & $\mathbf{N}$ \\
\hline $\begin{array}{l}\text { 4.1 Have you smoked at least } 100 \text { cigarettes in your entire life? } \\
\text { NOTE: } 5 \text { packs = } 100 \text { cigarettes }\end{array}$ & $\begin{array}{l}74.5 \% \\
\text { [Go to } \\
\text { Q4.6] } \\
\end{array}$ & $25.5 \%$ & $\begin{array}{l}0.0 \% \\
\text { [Go to } \\
\text { Q4.6] } \\
\end{array}$ & $\begin{array}{c}0.0 \% \\
{[\text { Go to }} \\
\text { Q4.6] } \\
\end{array}$ & 47 \\
\hline $\begin{array}{l}\text { 4.2 During the past } 12 \text { months, have you stopped smoking for } \\
\text { one day or longer, because you were trying to quit smoking? }\end{array}$ & $17.0 \%$ & $8.5 \%$ & $0.0 \%$ & $0.0 \%$ & 47 \\
\hline
\end{tabular}

\begin{tabular}{|l|l|l|}
\hline 4.3 When did you last smoke a cigarette, even one or two puffs? & Percentage & N \\
\hline Never smoked regularly & $\mathbf{0 . 0} \%$ & 47 \\
\hline 10 years or more & $19.1 \%$ & 47 \\
\hline 5-10 years ago & $4.3 \%$ & 47 \\
\hline 1-4 years ago & $2.1 \%$ & 47 \\
\hline 6-12 months ago & $0.0 \%$ & 47 \\
\hline 3-5 months ago & $0.0 \%$ & 47 \\
\hline 1-2 months ago & $0.0 \%$ & 47 \\
\hline 3-4 weeks ago & $0.0 \%$ & 47 \\
\hline 4-7 days ago & $0.0 \%$ & 47 \\
\hline 1-3 days ago & $0.0 \%$ & 47 \\
\hline Less than 1 day & $0.0 \%$ & 47 \\
\hline Don't know/ Not sure & $0.0 \%$ & 47 \\
\hline Refuse to answer & $0.0 \%$ & 47 \\
\hline
\end{tabular}

\begin{tabular}{|l|c|c|c|c|c|c|}
\hline & $\begin{array}{c}\text { Not at } \\
\text { all }\end{array}$ & $\begin{array}{c}\text { Some } \\
\text { days }\end{array}$ & $\begin{array}{c}\text { Every } \\
\text { day }\end{array}$ & $\begin{array}{c}\text { Don't } \\
\text { know / } \\
\text { Not sure }\end{array}$ & $\begin{array}{c}\text { Refuse to } \\
\text { answer }\end{array}$ & N \\
\hline 4.5 How often do you now smoke? & $25.5 \%$ & $0.0 \%$ & $0.0 \%$ & $0.0 \%$ & $0.0 \%$ & 47 \\
\hline $\begin{array}{l}\text { 4.6 Do you currently use tobacco, snuff, or snus? } \\
\text { NOTE: Snus (Swedish for snuff) is a moist smokeless tobacco, } \\
\text { usually sold in small pouches that are placed under the lip } \\
\text { against the gum. }\end{array}$ & $97.9 \%$ & $0.0 \%$ & $2.1 \%$ & $0.0 \%$ & $0.0 \%$ & 47 \\
\hline
\end{tabular}

Section 5: Fruits and Vegetables 
These next questions are about the fruits and vegetables you ate or drank during the last 30 days. Please think about all forms of fruits and vegetables, including cooked, raw, fresh, frozen, or canned, that you ate for meals, snacks and food you consumed at home or away from home. Circle the response that most accurately reflects how often you ate/drank them.

\begin{tabular}{|c|c|c|c|c|c|c|c|}
\hline & Never & Daily & Weekly & Monthly & $\begin{array}{l}\text { Don't } \\
\text { know } \\
\text { / Not } \\
\text { sure } \\
\end{array}$ & $\begin{array}{c}\text { Refuse to } \\
\text { answer }\end{array}$ & $\mathbf{N}$ \\
\hline $\begin{array}{l}\text { 5.1 Not counting juice, how often do you eat fruit? } \\
\text { (Count fresh, frozen, or canned fruit) (Do not include } \\
\text { jellies, jams, fruit preserves, dried fruit in ready-to- } \\
\text { eat cereals, dried raisins or Craisins, or fruit added to } \\
\text { yogurt, cereal, Jello or other meal items) }\end{array}$ & $0.0 \%$ & $48.9 \%$ & $42.6 \%$ & $4.3 \%$ & $4.3 \%$ & $0.0 \%$ & 47 \\
\hline $\begin{array}{l}5.2 \text { How often do you eat cooked or canned beans, } \\
\text { such as refried, baked, black, garbanzo beans, beans } \\
\text { in soup, soybeans, edamame, tofu or lentils. (Do } \\
\text { NOT include long green beans such as string beans, } \\
\text { broad or winged beans, or pole beans.) (INCLUDE } \\
\text { round or oval beans or peas such as navy, pinto, split } \\
\text { peas, black-eyed peas, cow peas, lima beans, white } \\
\text { beans, hummus, lentils, soy beans and tofu; include } \\
\text { falafel and tempeh; include bean burgers, including } \\
\text { garden burgers and veggie burgers.) }\end{array}$ & $4.3 \%$ & $6.4 \%$ & $59.6 \%$ & $25.5 \%$ & $4.3 \%$ & $0.0 \%$ & 47 \\
\hline $\begin{array}{l}5.3 \text { How often do you eat dark green vegetables, for } \\
\text { example, broccoli or dark leafy greens, including } \\
\text { chard, collard greens, turnip greens, mustard greens, } \\
\text { spinach, mesclun, romaine lettuce, bok choy, dark } \\
\text { green leafy lettuce, dandelions, komatsuna, } \\
\text { watercress, arugula, and kale? (Do NOT include } \\
\text { iceberg lettuce.) }\end{array}$ & $4.3 \%$ & $17.0 \%$ & $68.1 \%$ & $10.6 \%$ & $0.0 \%$ & $0.0 \%$ & 47 \\
\hline $\begin{array}{l}5.4 \text { How often do you eat orange-colored vegetables, } \\
\text { such as sweet potatoes (prepared in any way), } \\
\text { pumpkin (in pie or soup), winter squash like acorn, } \\
\text { butternut, and spaghetti squash, or carrots (include } \\
\text { all forms, except desserts)? }\end{array}$ & $2.1 \%$ & $8.5 \%$ & $51.1 \%$ & $34.0 \%$ & $4.3 \%$ & $0.0 \%$ & 47 \\
\hline $\begin{array}{l}\text { 5.5 Not counting the previous response, how often } \\
\text { do you eat OTHER vegetables? (examples of other } \\
\text { vegetables may include tomatoes, tomato juice or V- } \\
8 \text { juice, corn, eggplant, peas, lettuce, cabbage, } \\
\text { peppers (of all colors), okra, beets, cauliflower, bean } \\
\text { sprouts, avocado, cucumber, onions, cole slaw, } \\
\text { mushrooms, snow peas, snap peas, broad beans, } \\
\text { string beans, wax beans, pole beans, potatoes (not } \\
\text { fried), and any other form of vegetable (raw, cooked, } \\
\text { canned, frozen.) }\end{array}$ & $0.0 \%$ & $70.2 \%$ & $27.7 \%$ & $2.1 \%$ & $0.0 \%$ & $0.0 \%$ & 47 \\
\hline
\end{tabular}

